\title{
E-health Applications and Services for Patient Empowerment: Directions for Best Practices in The Netherlands
}

Laurence L. Alpay, Ph.D., ${ }^{1}$ Olivier Blanson Henkemans, Ph.D., ${ }^{1}$ Wilma Otten, Ph.D., ${ }^{1}$ Ton A.J.M. Rövekamp, Ing., ${ }^{1}$ and Adrie C.M. Dumay, Ph.D., M.B.A. ${ }^{1,2}$

${ }^{1}$ TNO Quality of Life, Prevention, and Care, Leiden, The Netherlands.

${ }^{2}$ Institute for Public Sector Efficiency Studies, Delft University of Technology, Delft, The Netherlands.

\begin{abstract}
Objective: E-health may enable the empowerment process for patients, particularly the chronically ill. However, e-health is not always designed with the requirements of patient empowerment in mind. Drawing on evidence-based e-health studies, we propose directions for best practices to develop e-health that promotes patient empowerment. Methods: The concept of patient empowerment in the Dutch setting is discussed first. The prerequisites for patient empowerment are then described and translated into empowerment areas relevant to e-health. Materials: We reviewed Dutch e-health studies that provide insights into what works, and what does not, in e-health. Results: On the basis of the lessons learned from the studies, we propose directions for best practices to develop e-health that promotes patient empowerment. These directions cover various aspects, such as the design and implementation of e-health, its information content and usability, awareness, and acceptance. The studies also indicate the difficulty of establishing that e-health is really dedicated to patient empowerment. Conclusions: Despite the body of knowledge about patient empowerment, as well as the technological visibility of e-health, evidence for best practices in general and for patient empowerment in particular is scarce. We call for a more systematic evaluation of e-health for patient empower-
\end{abstract}

ment and more reliable evidence. Beyond the organizational and technical issues involved in e-health, there is also a need to demonstrate its practical benefits to patients. The Netherlands is active in developing sustainable e-health. National initiatives are now in place to support the processes with the aim of establishing the required evidence-based best practices.

Key words: e-health, telemedicine, telehealth

\section{Introduction}

he age of the Dutch population is rising, imposing an increasing burden on the healthcare system. It is estimated that over 4 million people will be 65 years or older in 2030 , almost a quarter of the Dutch population. Further, recent Dutch reports indicate that the number of people with chronic conditions will continue to rise, whereas the number of healthcare professionals will decrease. ${ }^{1}$ If no action is taken and if the warning signs are ignored, it is expected that only limited care will be available for chronically ill patients by 2025. The warning signs are that the number of patients with dementia or cardiovascular disease is projected to grow by 45\% between 2007 and 2025; for every 100 of these patients today, there will be 145 in 2025. These are the fastest growing patient groups. Further, in 2025, the workforce will be $10 \%$ smaller than in 2007; for every 100 professional healthcare workers today, there will be 90 in 2025. Combining these two trends, it is expected that 55 of the 145 patients in 2025 will have no access to professional care, that is, a shortfall of $40 \% .^{2}$

To offset these scenarios, we have adopted a combined technology and empowerment approach as a way of making up for the $40 \%$ shortfall. In this approach, e-health technology is introduced for patients (to reduce the demand for care) as well as for healthcare professionals (to make work processes more efficient). Patients are 


\section{ALPAY ET AL.}

encouraged to carry out self-management activities with support from e-health, to transfer some care activities from the healthcare providers.

The term "patient empowerment" has been applied to a range of populations and settings. ${ }^{3}$ It is frequently used to describe a situation where patients are encouraged to be active in their own health management. Our viewpoint is that empowering patients can enable them to take more responsibility for managing their health and encourage self-management activities. Our view is also in line with Aujoulat et al., ${ }^{4}$ who put the patient perspective at the center of the empowerment process: "The goals and outcomes of patient empowerment should neither be predefined by the healthcare professionals, [...] but should be discussed and negotiated with every patient, according to his/her own particular situation and life priorities."

In The Netherlands, general practitioners play a central role in the allocation of care to patients. Approximately 97\% of general practitioners apply e-health. These technologies are mainly used for interprofessional interaction and communication (e.g., storing and sharing diagnosis, medication prescriptions) and not for physicianpatient interaction and communication. ${ }^{5}$ At the same time, a high percentage of Dutch households (86\%) have an Internet connection and older adults tend to search more for health-related information (30\% of 55-64 year olds).* However, the extent to which Dutch patients use e-health to manage their health is, to our knowledge, unclear. This is unfortunate, because e-health may foster patient empowerment. ${ }^{6}$

This article addresses the issue of patient empowerment through e-health. The prerequisites for patient empowerment are discussed first and translated into requirements for e-health. The lessons learned from four Dutch e-health studies are then described. On the basis of this evidence, we propose directions for best practices, with the aim of developing e-health tools that further patient empowerment.

\section{Materials and Methods REQUIREMENTS FOR PATIENT EMPOWERMENT AND IMPLEMENTATION MECHANISMS}

People gain greater control over their health if they are informed, skilled, and motivated. So patients should (1) have access to relevant information, (2) develop skills for problem-solving and self-efficacy, and (3) be motivated to manage their health. ${ }^{4}$ Different patientcentered mechanisms for implementing these requirements have

*From www.cbs.nl (Statistics Netherlands). been adopted, such as education and health literacy, decisionmaking aids, and self-care support. ${ }^{7}$ They are solutions to drive the empowerment process.

\section{E-HEALTH AS A MEANS OF ADDRESSING PATIENT EMPOWERMENT REQUIREMENTS}

We have grouped these requirements into four empowerment areas relevant to e-health. ${ }^{8}$

Insight into one's own health condition. This is a first step to more empowerment. For example, diabetic patients are faced with a variety of data about medical symptoms, nutrition, physical activities, medication intake, and glucose ratings. Managing these data personally can help patients to better comprehend their medical history, health status, and health prognosis. For instance, a personal health record (PHR), which facilitates entering, searching, personalizing, and sharing personal health data, can support this data management. Further, the PHR can provide patients with access to medical data from the electronic patient record.

Making informed choices. Deciding how to manage illness is a further step. This includes, for example, choices about different self-care options (e.g., medical procedures, medication intake, and lifestyle changes) and their consequences. Online decision aids can support decision-making by structuring the decision problem into the various options, and their consequences in a certain time frame. Subsequently, it can help the patient to assess the impact of the options on health (e.g., heart functioning) and lifestyle in accordance with norms and values.

Engaging self-care activities and developing self-care habits. Health management options that patients choose can be translated into self-care goals and daily self-care activities, while maintaining good quality of life. People with a kidney malfunction, for example, need to self-monitor their blood pressure and limit their salt intake. This can result in constraints on social activities and undermine healthy intentions. Coaching, through motivating attainment and maintaining personal health goals, can support developing self-care habits. However, this requires a shift in the healthcare service from traditional directive treatment toward monitoring, informing, and providing feedback, for example, through a computer coach.

Living independently. Patients' personal environments also contribute to empowerment. Older adults with early dementia, for ex- 


\section{E-HEALTH AND PATIENT EMPOWERMENT}

ample, will generally prefer to continue living independently in their safe and familiar environment. This means that they need to be more self-supporting and manage their disease with the help of their formal and informal care providers and services. To facilitate independent living, a house may require adjustments such as the use of robotics and access to a PHR. There should be a good fit between the patient's living situation, preferred care, and well-being.

\section{Results}

\section{EVIDENCE-BASED E-HEALTH FOR PATIENT EMPOWERMENT}

There are only a few rigorous studies that empirically demonstrate the benefits of e-health (e.g., Ref. ${ }^{9}$ ). Evidence in this area is also lacking in The Netherlands. More attention has been paid to developing e-health systems and services than to evaluating their merits. There is a lack of empirical evaluation of e-health for patient empowerment in particular. However, to improve e-health systems and services, we need knowledge about the elements that bring about desired outcomes (such as empowerment, economic benefits, and improvements in physical health) and undesired outcomes. In this section, we discuss four Dutch studies that provide some insights into what works and what does not in e-health.

Study 1. This study was a review of PHRs for self-care for diabetic patients. It looked at 76 patients and 65 healthcare professionals, addressing needs relating to, and experience with, PHRs. ${ }^{10, \dagger}$ The study focused on four aspects: insight into one's own medical data, data input, communication, and planning and monitoring. The main conclusion was that, despite the availability of various PHRs, patients hardly use them. The main reason is that patients cannot, in 97\% of cases, exchange information with their healthcare professionals. Similarly, a high percentage of healthcare professionals (89\%) have no way of exchanging information with patients. Other reasons for patients not using the existing PHRs are that (1) the PHR is not part of, or embedded in, the care process and (2) the PHR is seen as interesting for newly diagnosed patients only. In addition to the technical shortcomings, patients cannot always foresee the real benefit of using a PHR. One way of addressing this is to link the use of a PHR to an e-coach (a personal computer assistant), who provides patients with interpretation and guidance relating to the information from the PHR. ${ }^{11}$

Study 2. NICTIZ conducted another review of telemedicine for supporting independent living. ${ }^{12}$ Different experts, including pol-

\footnotetext{
${ }^{\dagger}$ NICTIZ is the National IT Institute for Healthcare in The Netherlands.
}

icymakers, health insurance companies, and advisors, were interviewed. From the patient perspective, such applications are not successful because (1) patients are not aware of the possibilities of these applications and do not know about them, (2) patients' needs and wishes are not addressed by the applications, and (3) patients have false expectations about financial arrangements. From the perspective of the professionals, the problem is a lack of incentives, and the lack of reimbursement for remote care remains a problem.

Study 3. A national health portal Kiesbeter.nl ("Choosing Better") was launched in 2005 so that consumers could find information about healthcare insurance and make informed choices. ${ }^{\star}$ Kiesbeter.nl now provides a wider range of health information, including decision aids. Our institute participated in their development. ${ }^{14}$ We drew a number of lessons. First of all, it took a long time (5 years) to collect the information. A lot of research and discussion involving a range of stakeholders was required. Second, after its initial launch, the portal remained relatively unknown. This triggered an information campaign in late 2009. Third, the presentation of the information (mainly in written form) needed improving. In the new version (2010), the information is organized better and displayed more visually. Nevertheless, more research is needed into how the information is used. A study of the use of decision aids indicates that further work is needed to support decision-making processes. ${ }^{15}$ Our study of the choice of hospitals for surgical treatment ${ }^{16}$ indicates that most patients prefer a summary measure about care quality to more detailed measures, but they seem to value a hospital's good reputation even more.

Study 4. One of the main challenges for e-health is to get past the pilot phase and become financially independent. With other stakeholders, we conducted a definition study, looking at how to implement the sustainable application of e-health services. ${ }^{17,8}$ This resulted in a list of a number of barriers that needed to be addressed, for example, in terms of healthcare culture, social basis, medical evidence, and technical standardization. Further, this study identified two important guidelines for overcoming these barriers. First, to be successful, the development of e-health requires a multidisciplinary user-centered design approach aimed at improving (1) patient involvement in the care process, and health and quality of life, (2) the satisfaction of the medical professional, and (3) the quality and efficiency of the care

During this period, a new Health Insurance Act came into force. ${ }^{13}$

${ }^{\S}$ Two medical insurance companies, a bank and a phone company (Menzis, Achmea, Rabobank, KPN). 


\section{ALPAY ET AL.}

process. Moreover, it looks at standardization to ensure that different technological innovations can be linked and can collaboratively support users and stakeholders. Second, a ground-breaking national plan is required, building on strong collaboration between caregivers, patients, insurance companies, the information and communication technologies (ICT) industry, and research, to develop a clear up-scaling road map supported by empirical evidence from living labs.

\section{Discussion}

The studies and the lessons learned provide some evidence for the use of e-health, specifically for patient empowerment. Overall, the studies indicate some directions required to achieve best practices in e-health. Although the proposed directions may not be solely dedicated to patient empowerment, identifying directions for best practices in e-health in a broader context is a step toward developing more focused e-health directives for patient empowerment.

- Design: A multidisciplinary user-centered design approach in the development of e-health applications and services can ensure that the needs of patients and professionals are being addressed.

- Implementation: Reducing identified barriers that prevent ehealth applications and services from getting past the pilot phase; embedding e-health in the care process.

- Information content: Collecting good-quality health information for consumers and patients, to help them make informed choices, takes time and is only a first step. There should also be a focus on information usability during that process.

- Awareness and acceptance of e-health by the healthcare professionals: Motivate healthcare professionals to use e-health, and bring about changes in attitude toward, and culture relating to, e-health.

- Awareness and acceptance of e-health by patients: Awareness of the possibilities (e.g., PHR combined with e-coach) and the practical benefits of e-health for self-management.

- Relationship between patient and professional: Ensuring that channels for e-communications and information exchanges are in place.

The studies also indicate the difficulty of establishing that e-health is really dedicated to patient empowerment. Requirements for the construction of e-health applications enabling patient empowerment as described earlier are not always visible or even included in the development of e-health applications. E-health applications and services are, at present, technologically visible. However, as illustrated by the studies, they are not yet widely used in practice. This technological availability is not adequate to ensure the sustainable use of e-health, specifically in terms of empowering patients.
Further, the practical benefits of this technology are not always clearly visible to patients. Focus groups, for example, in the SMASHING project with adolescents suffering from asthma, are a way of discussing the desirability and acceptability of e-health with patients. ${ }^{18}$

In The Netherlands, a series of national e-health initiatives launched in 2009 are paving the way for the development of best practices for e-health.

- The government Zorg Innovatie Platform: ZIP ("Platform for Innovation in Care")** aims to identify more good examples and evidence-based e-health.

- eHealthNu ("eHealthNow") $)^{\dagger \dagger}$ stems from the initial study reported in study 4 . It is based on broad scientific, commercial, and government experience, and it aims to provide guidance about how to implement the defined directives.

- The Landelijke actieprogramma Zelfmanagement ("National Self-Management Action Program") chronically ill patients to persist with self-management activities supported by e-health technologies. It aims to identify what works and also the good examples of technology use and knowledge sharing.

Research in the area of patient empowerment is also relevant as a contribution to the process of developing best practices in e-health dedicated to patient empowerment. Work in this area (e.g., Refs. ${ }^{3,19}$ ) may provide a sound basis for developing dedicated e-health applications and services and for understanding better the effects of patient empowerment and the conditions in which empowerment occurs.

\section{Conclusion}

Despite the body of knowledge relating to patient empowerment, as well as the technological visibility of e-health, evidence relating to best practices for e-health in general and for patient empowerment in particular is scarce. We call for a more systematic evaluation of ehealth for patient empowerment and more reliable evidence. Further, it is necessary to show patients that e-health is intended to improve their healthcare and empower them and is not simply a cost-cutting exercise. The Netherlands is active in developing sustainable ehealth. National initiatives are now in place to support the establishment of the required evidence base for best practices.

\footnotetext{
**http://zorginnovatieplatform.nl/.

${ }^{\dagger}$ www.eHealthNu.nl. TNO plays a coordinating role.

twww.zelfmanagement.com with the NPCF (Dutch National Federation for Patients; www.npcf.nl) and CBO (Dutch Institute for Healthcare Improvement; www.cbo.nl).
} 


\section{E-HEALTH AND PATIENT EMPOWERMENT}

\section{Acknowledgments}

The authors thank Ronald Mooij (TNO) for his valuable comments.

\section{Disclosure Statement}

No competing financial interests exist.

\section{REFERENCES}

1. Blokstra A, Verschuren WMM. Vergrijzing en toekomstige ziektelast. Prognose chronische ziektenprevalentie 2005-2025. Report RIVM 260401004. Bilthoven, The Netherlands: RIVM. 2007.

2. Goris A, Mutsaers H. Ruimte voor arbeidsbesparende technologie om in 2025 voldoende zorg te bieden. Leiden: STG/Health Management Forum, ISBN97890-75425-17-8, 2008.

3. Loukanova S, Bridges F. Empowerment in medicine: An analysis of publications trends 1980-2005. Cent Eur Cent J Med 2008;3:105-110.

4. Aujoulat I, d'Hoore W, Deccache A. Patient empowerment in theory and practice: Polysemy or cacophony? Patient Educ Couns 2007;66:13-20.

5. Dobrev $A$, Haesner $M$, Hüsing $T$, Korte WB, Meyer I. Benchmarking ICT use among General Practitioners in Europe-Final Report. 2008. Available at http://ec.europa.eu/information_society/eeurope/i2010/docs/benchmarking/ gp_survey_final_report.pdf (last accessed March 26, 2010).

6. Kushniruk AW, Borycki E. Human, social, and organizational aspects of health information systems. Hershey, PA: IGI Global Publisher, 2008.

7. Monteagudo Peňa JL, Moreno Gil O. E-health for patient empowerment in Europe. 2007. Available at http://ec.europa.eu/information_society/activities/ health/docs/publications/eh_era-patient-empower.pdf (last accessed March 26, 2010).

8. Blanson Henkemans OA, Alpay LL, Dumay ACM. Aging in place: Smart home environments. In: Mahmoud A, Al-Quitayri, eds. Smart home systems. Vukovar, Croatie: In-Tech Publisher, 2010:105-120.

9. Gustafson DH, Wyatt J. Evaluation of e-health systems and services. BMJ 2004;328:1150.

10. NICTIZ. Online zelfzorg voor de diabetespatiënt. 2009. Available at www.nictiz.nl (last accessed March 26, 2010).

11. Blanson Henkemans $O A$, van der Boog PJ, Lindenberg J, van der Mast CA, Neerincx MA, Zwetsloot-Schonk JHM. An online lifestyle diary with a persuasive computer assistant providing feedback on self-management. Technol Health Care 2009;17:253-267.
12. NICTIZ. Zorg op afstand met behulp van ICT. 2008. Available at www.nictiz.nl (last accessed March 26, 2010).

13. Ministry of Health Welfare and Sports. The new care system in The Netherlands. Durability, solidarity, choice, quality, efficiency. 2006. Available at www.minvws.nl/en/folders/z/2006/the-new-health-insurance-system-in-threelanguages.asp (last accessed March 26, 2010).

14. Raats CJ, van Veenendaal H, Versluijs MM, Burgers JS. A generic tool for development of decision aids based on clinical practice guidelines. Patient Educ Couns 2008;73:413-417.

15. Ossebaard H, van Gemert-Pijnen JEW, Sorbi M, Seydel E. A study of a Dutch online decision aids for parents of children with ADHD. J Telemed Telecare 2010;6:15-19.

16. Dijs-Elsinga J, Otten W, Versluijs M, Smeets HJ, Kievit J, Vree R, Van der Made WJ, Marang-van de Mheen PJ. Choosing a hospital for surgery: The importance of information on quality of care. Med Decis Making 2010 (In press).

17. Maas A, Mooij R, et al. Bruggen slaan tussen gezondheid, zorg en vrager. TNO Report 34999. Leiden, The Netherlands: TNO. 2009.

18. van der Meer V, van Stel HF, Detmar SB, Otten W, Sterk PJ, Sont JK. Internetbased self-management offers an opportunity to achieve better asthma control in adolescents. Chest 2007;132:112-119.

19. Alpay LL, Verhoef J, Xie B, Te'eni D, Zwetsloot-Schonk JHM. Current challenge in consumer health informatics: Bridging the gap between access to information and information understanding. Biomed Inform Insights 2009:2:1-10

Address correspondence to: Laurence L. Alpay, Ph.D. TNO Quality of Life, Prevention, and Care Wassenaarseweg 56 2333 AL Leiden The Netherlands

E-mail: laurence.alpay@tno.nl

Received: October 28, 2009

Revised: March 26, 2010

Accepted: March 27, 2010 